\title{
S+ (2) Nhận thức về giá trị có ràng buộc và cần điều kiện
}

\author{
Vương Quân Hoàng \\ Phenikaa University
}

Hà Nội, Dec. 6, 2021

Quay trở lại với bản chất của serendipity, là quá trình nhận thức có phần bất ngờ đối với chủ thể nơi quá trình đó xảy ra, tôi thấy đây là quá trình có điều kiện.

Trước tiên cần ví dụ cho cách hiểu này.

Năm 2018, gia đình chúng tôi có mùa hè ở Dijon, Pháp. Lúc đó con gái tôi đang học ở Dijon.

Sáng hai vợ chồng tôi thường đi ra siêu thị MonoPrix ở khu phố trung tâm mua vật phẩm sinh hoạt và thực phẩm. Trên đường đi ra chợ thường đi qua một công viên nhỏ, có tên gọi Darcy.

Một sáng, khi đi qua tôi nghe tiếng chim kêu nho nhỏ, kiểu "chiêm chiếp...". Tôi bảo bà xã đó là tiếng chim non. Công viên Darcy khá nhiều chim, nhưng tiếng kêu đó là chim tự nhiên (hoang dã). Nhưng rất khó đoán ở đâu.

Tới lúc về, khi đi qua chỗ nghe tiếng chim khi trước, thì không nghe tiếng kêu nữa. Nhưng thình lình có một con chim khá lớn, trông hơi giống chim sáo, nhưng lớn hơn, màu nâu đen (khá giống bìm bịp), bay vọt lên từ lùm cây, chỗ mà lúc nãy tôi đoán có thể có tổ chim.

Trên đường về nhà tôi ngẫm nghĩ có thể đó là chim mẹ. Nhưng vì trời cũng xâm xẩm nên thôi.

Tới sáng hôm sau, tôi quyết định khi đi qua sẽ tìm xem chỗ đó có tổ chim hay không. Khi tới nơi, thì lại nghe có tiếng chim non. Tôi đoán rằng hôm trước là lúc chim mẹ quay về có thức ăn, các cậu chim non không còn kêu vì đã được ăn. Nhưng sáng ra thì đói, lại chưa có mồi nên kêu. Vì thế, tôi tiến vào trong lùm cây, có động, tiếng kêu càng to.

Nhìn quanh không thấy cái tổ nào.

Nhưng nhìn kỹ, tôi thấy ở chạc tư của một cây, chỗ cao ngang đầu người, có một bọc to toàn rác bám xung quanh. Nghi đó là chỗ duy nhất có thể có tổ, tôi vít chạc cây xuống. Và như được đáp ứng mong đợi, 4 cái mỏ chim đang há hoác ra, kêu ầm ĩ, đòi ăn. Có thể thấy động chúng đoán là mẹ chúng về cho ăn, nên ngoác mồm ra chờ. 
Xem kỹ hơn thì mấy cậu này còn chưa mở được cả mắt.

Việc phát hiện ra tổ chim là điều rất vui. Niềm vui đó có lý do, và lý do đó sâu xa hơn chỉ là một phát hiện tình cờ. Tôi sẽ giải thích kỹ hơn việc này, vì lý thuyết mà tôi đề xuất trong cuốn sách này không có rằng đó là sự tình cờ như cái nghĩa dẫn xuất của từ serendipity, là serendipitous, thường ám chỉ. Sự tình cờ đó chỉ đóng vai một mảnh ghép thông tin, dữ liệu, cuối cùng để hoàn thành một chu trình tìm tòi, phát hiện. Nhưng việc giải thích đó sẽ chậm lại một chút, để tôi hoàn thành nốt các sự kiện xung quanh serendipity đã.

Phát hiện ra, hai vợ chồng tôi chụp ảnh kỷ niệm, quay lại một đoạn clip mấy cậu chim non đó. Rồi từ từ trả nó về vị trí cũ.

Tôi nhìn lại một lần nữa thì nhận thấy, quá trình làm tổ được sử dụng các nguyên liệu tự nhiên, có vẻ như rất sẵn có quanh vườn hoa. Chim bố mẹ khi đan tổ, có lẽ để tiết kiệm sức, đã tìm các vật liệu như rác, vỏ bọc ni-lông, một vài sợi dây buộc hàng, và có cả một số đầu mẩu thuốc lá.

Chi tiết cuối cùng khá quan trọng. Vì sau đó vài tuần, tôi có đọc một bài báo trên Science, trong đó có nói tới việc một số loài vật như chim biết sử dụng các vật liệu độc hại làm tổ để ngăn một số loài khác trong tự nhiên tấn công, cẳn phá. Hình ảnh tôi nhớ đến là đầu mẩu thuốc lá, thường có mùi hôi khét.

Một lần nữa sự tình cờ khiến tôi kinh ngạc về giá trị của việc lưu trữ thông tin có ích, ngay từ khi chưa thực sự có điều kiện đánh giá được giá trị của thông tin. Đây chính là nguyên lý cốt lõi của serendipity mà Nancy Napier và tôi đặt ra trong nghiên cứu [1].

Nhưng chuyện chưa dừng ở đây. Về lại Hà Nội, sự kiện tìm ra và gặp được các chú chim chưa mở mắt ở Darcy vẫn là một niềm vui nho nhỏ, nhưng rất đáng nhớ. Năm 2018, cuối mùa hè là lúc Hà Nội chịu cảnh lụt ở ngoại thành. Tin tức về lụt và cả thương vong được báo chí nhắc đến khá nhiều, kể cả báo chí quốc tế.

Một ngày khi mới về lại, tôi ngồi bàn việc với một vài đồng nghiệp ở quán café vỉa hè. Đang ngồi, tôi lại nghe tiếng chim non "chích chích...". Chỗ đó tôi biết rất rõ là không thể có tổ chim nào cả. Nhìn quanh thì phát hiện ra 3 chú chim non, đang học bay vì bay rất thấp, và chủ yếu nhảy lò cò. Tôi quan sát rất kỹ thì thấy, chúng chỉ nhảy loanh quanh một góc. Tôi bèn theo dõi kỹ hơn thì thấy chúng từ từ nhảy sát lại gần gốc cây bằng lăng, rồi tiến ra sát tường. Và chuyện hay xảy ra: chỗ tường ấy có môt ống nhựa nhỏ, là ông thoát nước thải của điều hòa nhiệt độ. Cục nóng nằm ở trên cao khoảng 5-6m, ống nước dẫn thẳng xuống sát chân tường. Mấy chú chim nhẩy lên bám ở gờ chân tường, và lần lượt đổi chỗ uống nước thải từ điều hòa.

Hình ảnh này striking. 
Và tôi không có gì ngoài chiến điện thoại cũ có máy ảnh (không tốt lắm) và phải chụp từ khoảng cách 6-7m. (Tiến đến gần thì chúng có thể sợ chạy đi mât)

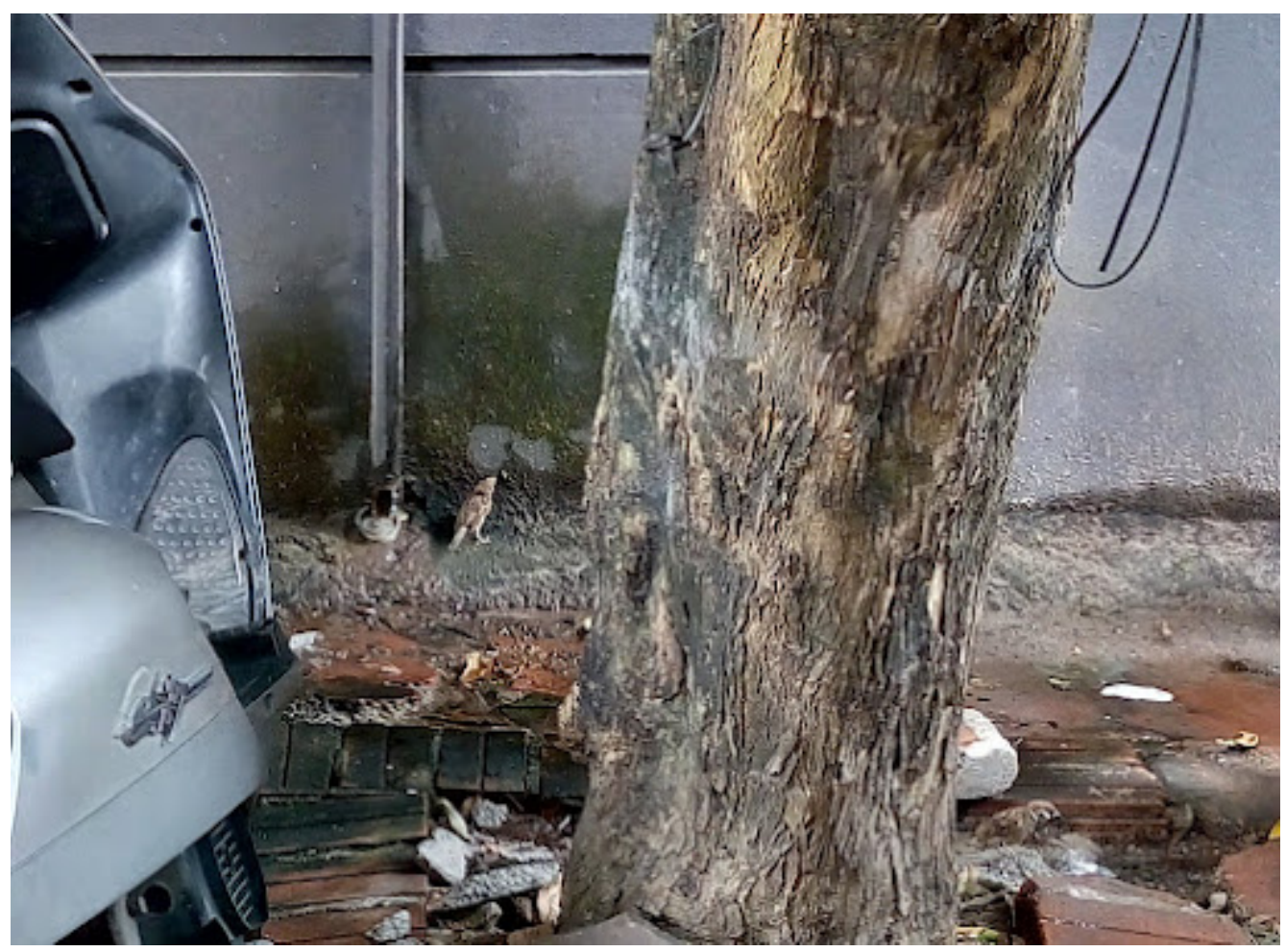

Hình chú chim sẻ uống nước thải điều hòa, chụp ngày 10-8-2018

Hình ảnh này làm nên sự tương phản trong suy nghĩ. Một thời điểm thành phố thì có những vùng lụt, ngập nước nặng do khồng tiêu được, và ở góc này, mấy chú chim đi tìm nước thải từ điều hòa để uống!

Nó là ý tưởng rất quan trọng để sau này tôi phát biểu mệnh đề về bất bình đẳng sinh thái, và đi đến nguyên lý bán dẫn về trao đổi giá trị môi sinh và tiền tệ [2]. Cũng sau đó một năm thì tôi đóng góp keynote address kèm theo bài cho hội nghị ASEAN Conference for Young Scientists, tổ chức ngày 2 tháng 12 năm 2019 tại Phenikaa University. Bài hội nghị đó sau hơn một năm thì đăng trên Journal of Sustainability Education [3], vào khoảng thời gian bài [2] chuẩn bị được chấp nhận công bố.

Trong bài [3] hình ảnh chú chim uống nước thải ra từ điều hòa có vị trí đặc biệt, xuất hiện khá sớm trong bài với giải thích cẩn thận về xuất xứ và ý nghĩa. Tuy vậy, một tác nhân ẩn đã không có điều kiện trình bày, đó là hình ảnh tổ chim ở Darcy, Dijon.

Loạt bài này, ngoài việc là kết quả công việc, nó còn ý nghĩa với suy nghĩ của tôi về môi sinh và về cả bản chất của việc phát hiện có liên quan tới tự nhiên, dựa trên cơ chế thu lượm đánh giá nhanh giá trị của thông tin, serendipity. 
Và, rõ ràng, nó không dừng lại. Tới đầu tháng 11 năm 2021, ngay cùng lúc với Hội nghị COP26, lúc đó Thủ tướng Việt Nam Phạm Minh Chính đóng góp những cam kết trong cuộc chiến với tác hại của biến đổi khí hậu, môi sinh toàn cầu, cùng với nhiều nguyên thủ quốc tế, thì một bài khác của tôi cũng trực tiếp đề cập tới sự bất bình đẳng trong nghiên cứu khoa học khí hậu ở quy mô toàn cầu, đăng trên tờ Economy, Land \& Climate Insight, của European Climate Foundation [4].

Như vậy, tôi tạm rút ra một mệnh đề nhỏ như sau. Hàng loạt công việc đã ra đời hoàn thành có nguồn gốc liên quan tới những giá trị thông tin tưởng chừng ban đầu là rất nhỏ, theo cơ chế serendipity. Nhưng chúng xuất hiện theo một lộ trình công việc, có cơ chế vận hành như hoạt động nghiên cứu và xuất bản trông dường như rất trật tự. Tuy điểm kêt nối có vẻ như khá mờ nhạt, khó thây, nhưng lại rất logic và chắc chắn, chứ không lỏng lẻo hay yếu ớt.

Điển hình là các mệnh đề phát biểu ngắn gọn, súc tích trong bài [4], chính là một liên kết tới hàng loạt kết quả công việc, mà để đảm bảo tính minh bạch, chỉnh thể, tôi đã dẫn ra 4 bài đã xuất bản trong phần tài liệu tham khảo. Ở đây, tôi muốn nhấn mạnh yếu tố hệ thống được "hoàn chỉnh" nhờ một vài mẩu thông tin hữu ích cuối cùng, như tổ chim ở Darcy, hay chú chim uống nước điều hòa. Serendipity rõ ràng là keyword.

Tuy nhiên, cuốn sách này không tập trung vào "khai thác" giá trị của serendipity mà nhằm lý giải cội nguồn sinh ra nó từ con người, theo cách lập luận của tôi. Do đó, phần tiếp theo đây là tiếp nối quan trọng.

Vậy tại sao tính chất "có điều kiện" lại quan trọng?

Trước tiên, tôi phải nói ngay rằng, thông tin, hình ảnh hay âm thanh từ tiếng chim non quan trọng đối với cá nhân tôi, trong hệ văn hóa và mối quan tâm của tôi, nhưng có thể hoàn toàn rất ít giá trị với một người khác. Như vậy, tầm quan trọng của thông tin ấy là một thứ "có điều kiện".

Và đây là mấu chốt vấn đề.

Chỉ khi, trong nhận thức, hệ văn hóa-giá trị bản thân, xu hướng đánh giá cao giá trị thông tin ấy tồn tại, thì cơ hội thông tin được tiếp nhận mới tăng lên. Nếu không, nhiều khả năng sẽ bị loại bỏ từ sớm, do có rất nhiều thông tin từ môi trường liên tiếp tác động lên chủ thể xử lý thông tin.

Trong trường hợp tiếp nhận thông tin tiếng chim kêu ở Darcy của tôi nó xảy ra như sau, dựa trên một lịch sử rất lâu dài, nuôi dưỡng giá trị của hình ảnh chú chim, cùng với liên kết môi trường sống.

Mùa thu năm 1977, tôi là đứa trẻ lần đầu chập chững đi học lớp học phổ thông đầu đời. Trong bài tập đọc hay có các hình ảnh. Trong 
sách có nhiều hình khác nhau, giúp học sinh bé nhận biết và tạo điều kiện đánh vần, ghép âm dễ dàng hơn, như quả na, con thuyền, tổ chim, v.v.. Và có một chuyện rất ấn tượng xảy ra. Có một người bạn trong lớp, tên gọi là Hưng, được cô giáo gọi lên yêu cầu đánh vần. Do mải chơi, và không để ý trong giờ học, nên khi cô giáo bảo đánh vần đọc từ trong hình đầu trang số xyz, thì cậu bạn vì lý do nào đó nhảy xuống hình dưới, và hô rất dõng dạc: - Thưa cô, cái tổ chim ạ.

Đám trẻ con cười ồ lên.

Tât cả những ai học thì đều biết, thứ nhất là bạn này làm sai yêu cầu. Đó không phải là hình mà cô giáo muốn đánh vần. Nhưng bạn này có vẻ như thích tổ chim quá, nên nhảy xuống hình đó. Hai nữa, cái từ đó không phải là "Cái tổ chim" mà chỉ là một từ đơn, nếu tôi nhớ không nhầm là "tổ" thôi. Nhưng hình thì đúng là cái tổ chim, nên cứ hô lên cái tổ chim. Ba nữa là sai yêu cầu, vì để học đánh vần thì ghép từ, đánh vần rồi phát âm. Đối với trẻ con chúng tôi lúc đó, việc làm sai một lúc cả loạt việc như thế rất buồn cười. Sau đó, cậu bạn này được ghép luôn biệt danh "Hưng tổ chim".

Cũng chính vì ấn tượng của sự kiện này, vì học sinh lơ đãng, làm sai, và phạm lỗi sẽ bị quật thước kẻ vào tay, tôi càng chú ý đến cái tổ chim trong sách. Và tôi thấy hình ảnh minh họa của họa sỹ rất đẹp. Cũng không khó để nhận ra con chim đan tổ rất khéo. Và con chim non trong tổ rất sinh động, đáng yêu. Nhưng trẻ con ở trong phố Hà Nội thì lấy đâu ra tổ chim mà xem? Suy nghĩ về việc được xem cái tổ chim thật ở thiên nhiên nó cứ lớn dần. Và nó chẳng bao giờ được đáp ứng. Chim thì vẫn thấy bay và hót trên lùm cây, nhưng khồng bao giờ có dịp thấy tổ chim ở thiên nhiên, càng chẳng bao giờ được thấy con chim non đang ở trong tổ, há ngoác mồm chờ ăn như ở Darcy năm 2018.

Sau đó một thời gian ngắn, trong cùng khu nhà tập thể của tôi, có một cậu bạn cùng lứa tuổi nhặt được một con chim non. Nó là chim sẻ non. Lúc đó, tôi đã đủ quan sát để biết chim sẻ màu gì, và sống tự nhiên ra sao. Cậu ta khoe con chim, và chỉ cho tôi biết một kiến thức quan trọng, về sau này đôi lúc vẫn có ích. Đó là, ở hai bên cạnh mỏ của chim sẻ non (mép mỏ) là màu vàng!

Đây là một hiểu biết vĩ đại đối với đầu óc non nớt của tôi lúc đó! Quả nhiên, sau một thời gian nuôi đủ lớn, thì màu vàng biến mất dần, chỉ còn màu nâu đen.

Điều kỳ diệu xảy ra, cậu bạn tôi đang ngồi chơi huýt sáo, và con chim bay ra đậu vào tay cậu ấy.

Cái ý niệm về việc có thể huýt sáo gọi con chim đậu lên tay hay vai càng vĩ đại và lớn lao hơn. Tôi có thử vài lần huýt sáo, nhưng nó không bay ra chỗ tôi. Tôi khâm phục cậu bạn này ghê gớm vì quyền năng của cậu điều khiển con chim vốn là loài hoang dã, chưa tới gần đã bay. Sự khâm phục này của tôi chỉ chấm dứt, khi cậu bạn buồn bã 
báo là con chim của cậu ấy bị con mèo của nhà vồ và ăn mất sau đó ít lâu.

Tuy nhiên, sự kỳ diệu của tiếng huýt sáo và con chim bay tới đậu là một thứ phản ánh quyền năng ghê gớm. Nó đã kịp khắc sâu vào trong óc mất rồi.

Mãi những năm tháng sau đó, đi đâu có cây, có tiếng chim, tôi cũng vẫn có thói quen tìm xem quanh đó có tổ hay không. Thật không may, chưa bao giờ được nhìn thấy tổ chim trong thiên nhiên. Tuyệt nhiên không, và một lần cũng không.

Tới khi lớn hơn, trong một lần đi học ở nhà bạn, trong khuôn viên trường ĐH Giao thông vận tải Hà Nội, lúc đó khá hoang vu ở Cầu Giấy, tôi tình cờ chứng kiến cơn gió lắc cây phi lao, và một cái tổ chim rơi từ trên cao xuống. Lúc đó tôi khoảng 15 tuổi. Đó là cái tổ chim đầu tiên tôi thấy và vô cùng sung sướng được tận tay cầm tổ chim. Nó được đan bằng lá cây phi lao. Mà lá phi lao khô màu nâu vàng, kích thước gần như đều tăm tắp. Cái tổ đan khéo vô cùng. Đẹp kỳ diệu. Nhưng không có con chim nào. Có vẻ đó là tổ đã bỏ, sau khi ấp xong trứng nở và chim mẹ đã dậy chim con bay, tự lập rồi.

Rất vui, nhưng cũng rất tiếc nuối, vì vẫn chưa được thấy trứng hay chim ở trong tổ.

Mong muốn chỉ có lớn lên, cho dù tuổi nhiều lên và công việc thì hầu như chẳng có gì liên quan tới tổ chim cả.

Tuy vậy, khi tới năm 40 tuổi thì tôi được mãn nguyện. Trong một lần đưa các con về quê chơi và đi thăm khu nghĩa trang gia đình, tôi đi thăm hai hàng cây cảnh nhỏ trồng dọc đường đi. Tình cờ, tôi nhận thấy có vật gì to dài, nâu nâu bám dọc thân cây. Cây đó là cây lúp xúp dạng bưi, chứ không phải cây lớn. Và tiến tới nhìn thật kỹ, thì tôi nhận ra đó là một tổ chim. Lớn, đan rất khéo và chắc. Nằm ở vị trí cũng không dễ nhận biết, và bên trong khu nghĩa trang có tường bao quanh (ít trẻ con vào nghịch ngợm). Khu nghĩa trang nằm giữa ruộng lúa ở đồng quê, thuộc Bắc Giang.

Nhìn vào trong, tôi sửng sốt nhận ra có 5 quả trứng chim nho nhỏ.

Sau đó 2 năm, cũng tại khu nghĩa trang này, tôi lại bắt gặp một tổ chim khác, nhưng nằm ở vị trí khác là giữa đám cây dại nhiều gai, gọi là hoa xuyến chi. Một tổ rất đẹp, và ở trong chỉ có 1 trứng duy nhất. 


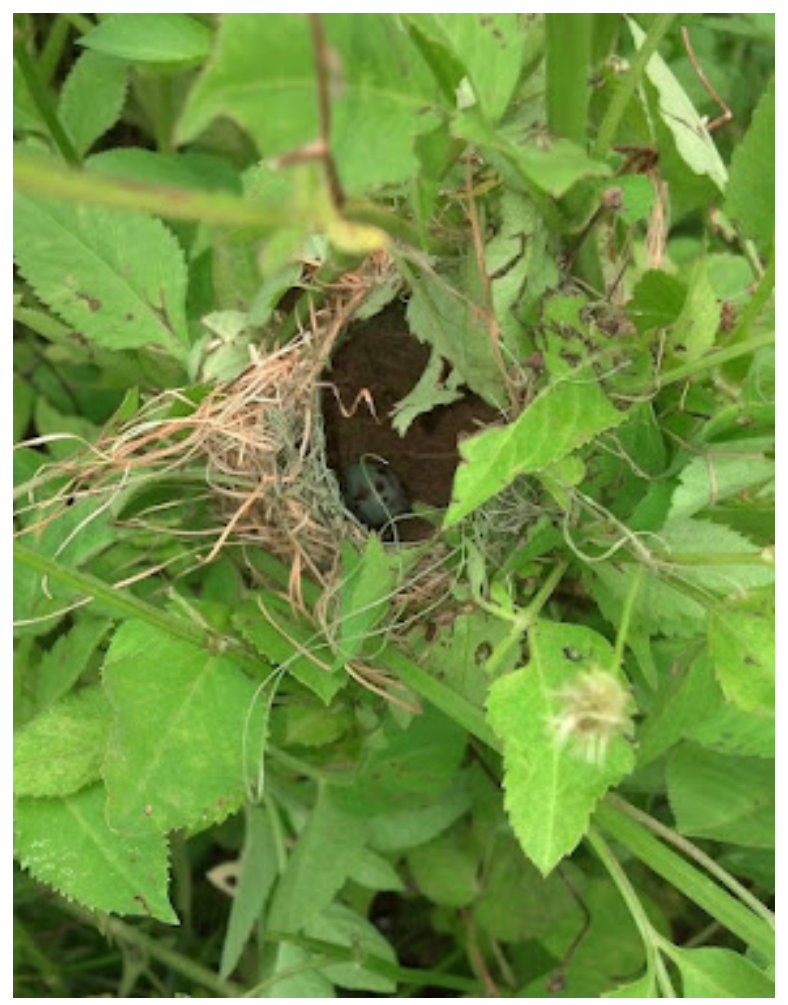

Tổ chim sâu chụp được ngày 26-3-2013

Tới năm 2015, tại nhà riêng có vườn rộng trồng nhiều chuối ở gần hồ Đồng Mô, Sơn Tây, lần đầu tiên tôi có được cảm giác có tổ chim làm ngay trong nhà mình, cách tường nhà chỉ vài mét, nơi một bụi chuối mọc bám sát tường rào. Đó là tổ chim sâu, được làm bằng cách khâu hai mép lá chuối lại, và dệt thêm xung quanh một sổ loại rác mà chim bố mẹ nhặt được quanh đó. Đây chính là cách mà tổ chim ở Darcy được xây nên. Chính việc nhìn thấy chim mẹ và mấy chim con tâp bay vọt ra từ cái tổ ở vườn nhà này, mà tôi đã không bỏ qua thông tin cái búi rác nằm giữa chạc tư của cây ở Darcy.

Điểm rất quan trọng trong hệ thức tìm kiếm và đánh giá nhanh giá trị thông tin theo cơ chế serendipity tôi muốn nêu sau tất cả những trình bày dài dòng này là:

Giá trị của thông nhanh thu lượm được sẽ tùy thuộc vào sự tích lũy thông tin, việc ngầm định giá trị của một số loại thông tin liên quan đến đối tượng (ví dụ, con chim, tổ chim), và một số hiểu biết, kỹ thuật nhận biết (tức là thông tin tích lũy quá khứ).

Đôi khi, giá trị này được tích lũy qua thời gian rất rất dài. Thời gian dài có hai nhiệm vụ gần như đồng thời. Một mặt, loại bỏ đi những thông tin và giá trị không còn được quan tâm nữa. Mặt khác, nếu sau quá trình khử bỏ đó mà những thứ còn lại vẫn được quan tâm, thi thoảng lại trỗi dậy gây thắc mắc, thì câu hỏi (sự tò mò) sẽ càng lớn hơn. Khi mẩu thông tin như tổ chim ở Darcy hay con chim uống nước điều hòa xuất hiện, nó có thể đủ mạnh để hoàn thành cả các ý tưởng nghiên cứu đang dang dở, hoặc thậm chí thúc giục một ý tưởng đang ấp ủ tiến tới giai đoạn bước vào thực thi, bớt đi sự chần 
chừ.

Dù là trong trường hợp nào đi nữa, thì cơ chế serendipity thực sự hoạt động dựa trên việc tiếp thu, đối sánh thông tin với sự phù hợp về cách đánh giá giá trị nội tại của chủ thể xử lý thông tin.

Và đây là cửa ngõ đi vào bên trong cơ chế khởi sinh quá trình serendipity.

\section{References}

[1] Napier, N. K., \& Vuong, Q. H. (2013). Serendipity as a strategic advantage?. In: T. Wilkinson (ed.) Strategic Management in the 21st Century (pp. 175-199). Praeger/ABC-Clio.

[2] Vuong, Q. H. (2021). The semiconducting principle of monetary and environmental values exchange. Economics and Business Letters, 9(3), 284-290.

[3] Vuong, Q. H. (2020). From children's literature to sustainability science, and young scientists for a more sustainable Earth. Journal of Sustainability Education, 24(3), 1-12. Retrieved from: http://www.susted.com/wordpress/wp-content/uploads /2020/12/Quan-Hoang-Vuong-JSE-December-2020-GeneralIssue-PDF.pdf

[4] Vuong, Q.-H. (2021). Western monopoly of climate science is creating an eco-deficit culture. Economy, Land \& Climate Insight. Retrieved from: https://elc-insight.org/western-monopoly-ofclimate-science-is-creating-an-eco-deficit-culture/ 